\title{
Outcomes Based Performance Appraisal of ET Managers Using Forced Ranking System
}

\author{
Tim Wiley and Hamid Khan \\ Northern Kentucky University
}

\begin{abstract}
Literature is replete with studies of performance appraisal systems used in Engineering Technology (ET) personnel reviews and those studies conclude that the performance appraisal systems are not above reproach, and that there are inherent problems with any performance appraisal system. A further review of literature uncovered a number of alternatives for the potential problems associated with the performance appraisal systems for technical managers, and their lack of effectiveness. For this research study, the inherent problems of performance appraisals using 'forced ranking system' was investigated and the adverse effects of forced ranking of technical managers was examined.
\end{abstract}

In many organizations peers, employees and managers have begun to experience the adverse effects of the use or misuse of forced ranking. Without warning, employees experience feelings of loss, grief and resentment for receiving the brand or label of a "poor performer." Certainly, there is a need to analyze and identify employees that require encouragement to become more productive, but a company should refrain from creating an atmosphere of fear causing its staff to question their reason for continued employment.

This research was designed to determine the effect of forced ranking system (FRS) on employee performance and productivity. It is hypothesized that performance and productivity are negatively affected by a forced ranking system of performance appraisal.

The null hypothesis is $H_{o}: \mu_{1}=\mu_{2}$. The alternate hypothesis is $H_{1}: \mu_{1} \neq \mu_{2}$. (control group $=1$ and experimental group $=2$.) The hypothesis will be tested by the responses of a sample of respondents from business and industry.

\section{PROBLEM STATEMENT}

Literature review found that performance appraisal systems are not above reproach, and that there are inherent problems in any kind of performance appraisal systems. A number of alternatives were examined as potential projects of research with the problem of performance appraisal systems and their effectiveness. For this research study, the inherent problems of performance appraisal using forced ranking system will be investigated and the effects of forcedranking as an effective appraisal method will be examined for the technical personnel. 


\section{INTRODUCTION TO THE PROBLEM AND BACKGROUND}

According to Oberg (2002), Performance appraisal systems began as a single method for justifying employee income [1]. This research will focus on performance appraisal system of Engineering and Technology personnel as the target of population. Pay incentives were originally distributed on a contractual percentage basis to unionized employees (like the percentage increases agreed to at the beginning of a multi-year union contract). Salaried employees would receive a percentage bonus from a pool fund. Depending on the overall profitability of the company, a percentage of the "pool" fund would be distributed to department ET heads for redistribution to salaried staff. Determination of the redistributed monies was based on individual performance evaluation of employees.

For a number of years, companies used the Performance Appraisal Review System (PARS) to evaluate individual employee performance. PARS was replaced with its better counterpart MBO or Management by Objectives. The desire was to move the appraisal process away from possible managerial or supervisory pandering as was possible with PARS. The areas of performance were hard to quantify and therefore lent themselves to subjective interpretation and the influence of the relationship between rater and those being rated.

On the other hand, management by objectives (MBO) was guided by mutually agreed upon objectives. The ultimate goal was to encourage that the employees work as a team and collectively strive to meet or surpass corporate and departmental objectives. The MBO process eventually gave way to KRA or Key Result Areas.

KRA was similar in basic methodology to MBO but could more effectively quantify the work produced by the employee and track the completion of specific objective items. With the adoption of KRA, a related "initiative" was enacted, the use of employee ranking.

The ranking procedure required the identification and classification of quintile percentages. Each employee would receive a KRA score ranging in value from 0 to 3 . The managers would then meet with executive leadership and elect or place each employee into one of the five-quintile sectors. Most of this selection was based on the KRA score but the defining factor was the extreme bias of the manager and how they viewed the value of the employee to their department.

The quintile classification was divided into the following categories:

- Top 20\% - Largest percentage of pool funds

- Next $60 \%$ - Average distribution of pool funds

- Bottom 20\% - Smallest percentage of pool funds*

*The bottom $20 \%$ was additionally categorized into the very bottom $5 \%$. These individuals were treated as a pariah to the rest of the worker community. They were silently marked as employees that had failed to "make the grade." The bottom $5 \%$ club received no pay increase and was informed that they had one year to improve and move from this category or face possible termination. Grote (2002) critically studied such performance evaluation systems and suggested overhaul and re-appraisal of those systems [2].

Proceedings of the 2003 American Society for Engineering Education Annual Conference and Exposition Copyright (C) 2003, American Society for Engineering Education 
The desirability or the most important influence of performance measures is to improve the productivity of the business practices within the organization, and not to impede its progress toward that goal. For this to occur, the measure must be evaluated as to its ability to improve the workplace, to define its ability to create a positive atmosphere for teamwork, and to determine if the measure embodies motivational change.

Many researchers and writers have addressed the use of performance management and measurement systems. Knudson's (1989) classical study focused on performance evaluation of academic and administrative leaders at Harvard University [3]. This study was partially replicated by Khan in his Purdue University study of management development for ET managers. Khan (1996) studied the 'effective management development program evaluation and review technique' and consequent effects on performances of practicing ET managers [4]. This study uncovered the 'perceived rankings of importance of and competence in managerial tasks' as a measure of ET manager's effectiveness - hence it used the managerial task-performance on the job as a tool to avert a subjective evaluation of supervisor who applied forced ranking. Khan's (1996) findings of managerial effectiveness and those managers' consequent preparedness for excellent performance, were in direct contrast with forced ranking method applied in many organizations-- some of the forced rankings being too subjective to defend the merit of company's lean-mean objectives in severe budgetary crisis.

The study found the following "abilities" of ET managers as armors against subjective forced ranking.

1. Demonstrated ability in building trust with peers, superiors

2. Ability to establish priorities, and setting goals

3. Effective writing: expressing ideas correctly

4. Clearly understanding clientele (and customer) needs

5. Ability of budgeting managerial work time

6. Showing and having flexibility: varying behavior

7. Clearly has demonstrated impact with ideas and oral presentations

8. Takes initiative to assume responsibility

9. Directs program and project for implementation

10. Demonstrates the art of delegating, coaching, and providing follow-up

IBM, however, practiced 100\% guaranteed employment to their ET managers in 19701980 because it believed that today's best mangers could never be equated as the worst ones next year! IBM never used the forced ranking method of bell-curve evaluation because it could not be defended, until severe crisis hit the company due to external threat of competition as the entry to pc became easy and IBM's global dominance was reduced precipitously. Later researches have not quite honed in on the area of employee ranking (by forced ranking or forced distribution of bell curve) and its effect on employee morale. It is believed that this study will shed light on the results of past research, by employing a survey instrument to solicit and uncover the adverse effects of forced ranking of technical managers who were once excellent performers. This comparative investigation will seek to corroborate the effects of continued use of forced ranking on the productivity of the technical employee and the company. 


\section{REVIEW OF LITERATURE}

The information for this research can be separated into six distinct categories, indicating the following major themes: Lines of communication, "Performance and pay" issues, Performance appraisals, Quality of work life, Employee morale, and Ranking. Only a few authors specifically stated a case for elimination of the forced ranking process, but we will discuss this issue further in the conclusion. The majority of works were concerned with the use of a performance appraisal system to replace conventional pay systems. William Abernathy [5], in his significant work entitled Sin of Wages, alleged that employees who are a part of a conventional pay system have developed "entitlement thinking" and that they are part of an "entitlement culture." Abernathy [5] continues by stating that this thought style "has created a nation of risk-averse employees who refuse accountability and are unwilling to accept the cold fact that without a successful business there can be no pay." I oppose this line of thought because, in my opinion, the majority of workers are content with their jobs because they perform well and are responsible for their link of the chain. Their level of responsibility helps to reinforce their loyalty and commitment to the organization.

The ability to properly communicate is a foundation that continues to stigmatize employers and their employees. Case in point, a survey conducted by one company. Employees had long held that upper management never listened to the needs or opinions of the worker. The business thought that the best way to address the problem would be to find out how the employee viewed the company. After the survey was completed and results were calculated, management determined that the workforce felt there was "dead-wood" and "they would never lose their jobs." What the employee meant by answering the associated question was there were a few employees that needed correction in their specific work habits and may need to be eliminated from employment. In addition, approximately $83 \%$ responded that they felt their employer was a stable and secure place to work. What management read into the results was that employees were generally lazy and needed a wake up call. Not only did they need to identify the "dead-wood" but also they needed to make a clear statement that no position within the company was secure, nor should anyone feel stable. In a completely unstable world, the one thing that needs to remain as much of a constant as possible is the workplace. Researchers like (Schellenberger, 2000) who analyzed employer-employee communication and relationships have found that the employee wants the employer to demonstrate "caring and concern toward them" [6]. Peter Stark in (Toth, 1999) stated that "employees are looking to be cared about, valued, communicated to and recognized for the work they do" [7].

Performance and pay issues focused on analyzing the use of performance appraisals by supervision and teams. How effective each was at properly assessing performance and how each dealt with those labeled as "poor" performers. Performers that received less than expected ratings produced an additional study that analyzed "targets of blame" (Longenecker; Liden; \& Taylor, 1999 [8]). While none of their findings or analysis supported the need for a deeper look at employee ranking, author Claire Lousie Stone cited the need for performance to focus not just on performance of the individual but on the "soft issues" (Stone, 1996) [9]. Performance measurement must rely on both hard and soft measures. Hard measures are those that are fairly quantifiable and objective. Soft measures are those that are more behavioral in nature such as morale, employee satisfaction, communication issues, and pride and commitment for the 
workplace. It is likely that the most effective appraisal method is one that employs both objective and subjective aspects instead of those looking solely at the bottom-line.

In analyzing the types of appraisal methods and how they are currently viewed, Rensis Lickert made the following statement with regard to employee performance appraisal. "The aim of reviewing the subordinate's performance is to increase his effectiveness, not to punish him. But apart from those few employees who receive the highest possible ratings, performance interviews, as a rule, are seriously deflating to the employee's sense of worth...not only is the conventional performance review failing to make a positive contribution, but in many executives' opinions it can irreparable harm." Clearly, whatever system is used it must incorporate the following: participation and feedback by the employee and the use of soft issues or "behavioralbased criteria" (Glover, 1996) [10]. This will ensure that the employee is being judged per objective and subjective standards.

The aspect of the research with regard to the quality of work life was displayed in the following observations. One body of research found that "the nature of an employee's psychosocial working conditions or quality of work life can have a strong effect on his or her well-being and performance" within the organization (Donaldson, 1999) [11]. Their research has defined the following factors as traits of QWL. They are as follows:

- the general work environment,

- coworker relations,

- quality of supervision,

- job satisfaction,

- job security, and

- level of stress.

These quality-of-work-life factors help to predict the level of organizational commitment and the frequency of employee tardiness. On the other hand, performance appraisals that use the forced ranking process create an atmosphere of fear. The fear portrays itself in the form of increased use of sick time and lost productivity. There is a lack of commitment by the employee due to their decreased belief in displaying loyalty to the organization. "Fear takes the form of tentativeness in the face of uncertainty. Fear can never be driven from the workplace if work becomes a marathon in which only those with enough stamina survive." (Briksin, 1996) [12] Businesses must avoid the use of forced ranking as part of the appraisal process so that an organization can positively grow.

As for morale, research indicated that the "key to good morale (within an organization) is found in how management relates to its workforce." (Martin, 1999) [13] It is also suggested that the first step to improving morale be centered on the "establishment of trust." Good worker morale translates into improvements in productivity, cost-savings and reduced employee turnover. Businesses that continuously demonstrate a competitive edge over their competition demonstrate a high morale factor. For organizations looking to identify low morale, they should look for the following five signs: poor attitude, increased absenteeism, increased accidents, reduced productivity, and body language. 
Finally, the research process indicated that the use of forced ranking was a negative influence to the overall performance appraisal system. Jack Zigon stated that forced ranking causes "dysfunctional competition because it compares employees to each other" instead of to performance standards. (Zigon, 1998) [14]. Xerox focused on improving its performance appraisals because a major complaint from surveyed employees stated that there was a "lack of equitable rating distribution." (Deets, 1986) [15]. Hitchcock (1996) [16] wrote that rating or ranking of employees should be based on objective not subjective standards. We determined earlier that the best appraisal methods would be those that combine the use of objective and subjective standards but the subjective standards must be behavioral-based and not hinged to the bias of the rater.

So, Forced ranking may be possibly best defined by individual word analysis. To be forced is to use an adjective that qualifies that an act is performed or brought about against the will of the individual, an act not voluntary or natural. Ranking or rating is a noun that is defined as a placement in a certain rank or class.

Profit and productivity round out the operational definitions for this project. Profit may be termed as the revenue gleaned after operating and overhead expenses have been accounted for. Productivity is the amount of product or service produced during a given period-of-time.

\section{RESEARCH METHODOLOGY}

A number of respondents were encouraged to participate in the survey process in both the control and experimental groups. A maximum number of 25 were solicited. Convenience sampling was used for conducting this survey due in part to the time constraints of the project and the ability to successfully obtain sufficient participation for research dependability and reliability. The number was chosen was due to their availability and survey participation interest.

The initial survey instrument was prepared and distributed to a pilot group of 5 employees to analyze the overall product clarity, coherence, and usefulness for obtaining respondent opinion. Individuals analyzed the survey based on grammar, its ability to capture respondent opinion, and the ability for respondents to role-play after reading the cases study portion. Revisions were made to the instrument after the pilot group completed its analysis.

The instrument used was a qualitative survey that included a case study scenario to elicit respondent opinion. All of the opinion statements revolved around the level of satisfaction respondents held regarding various aspects of the business culture affecting those respondents. Practices included their overall opinion of job satisfaction, morale, quality-of-work-life, and their performance appraisal system (or performance review process). The case study portion was employed due to the possibility of a respondent not currently participating in a review process. This would allow the individual to read the case study and then role-play by answering the rest of the survey from the point-of-view of the main character in the case study.

A comparative analysis, using chi-square, was completed of survey findings and their individual employee profiles. The profile gave direction to the researcher as to whether responses were chosen based on years of service, age, gender, education, salary, type of business, or a combination of these factors.

Proceedings of the 2003 American Society for Engineering Education Annual Conference and Exposition Copyright (C) 2003, American Society for Engineering Education 
Each participating company had an on-site survey administrator. They were responsible for delivering the test in paper form, or the survey was downloaded from a known ftp (file transfer protocol) site via the internet. The on-site administrator will distribute, collect, and return the completed surveys to the researcher. All surveys were administered, completed and returned by $9 / 17 / 02$. This was necessary to allow sufficient time for data analysis and submission of findings to the research administrator by $9 / 30 / 02$.

\section{RESEARCH DESIGN}

For this research, the data collection was experimentally designed to first identify respondent's opinions of their current business culture. The employee survey process, in its design explores current business culture and employee profile. Prior to feedback, two areas must be addressed at the conclusion of the data analysis - survey validity and reliability. Validity is the level with which a survey measures each survey topic. Reliability is determining how consistent the survey is over time. In addition, the level of correlation survey items have with each one another will be investigated. If a survey is unreliable, survey statistics will move up and down without respondent opinions really changing. What may look like a significant change may be due to the unreliability of the survey method.

The study's experimental group, mu2, consists of responses from employees whose organizations currently employ a generic performance evaluation method. The control group, mu1, represents responses by individuals whose organization uses performance evaluation with a forced ranking system.

\section{RESULTS}

In discovering employee opinion regarding the use of forced ranking, surveys were prepared in paper and electronic format. The electronic format was discussed with a few human resource forums for their consideration to participate. It was prepared as a zip file and stored on an ftp (file transfer protocol) site for interested participants to download. Locally, the survey was prepared in a collective format; as a case study to help respondents that had never participated in a performance appraisal and the other, as a standard Lickert-type survey. The survey was submitted to twenty-five respondents from 3 companies. The employees of those companies currently participate in a performance appraisal and forced ranking process. Twenty-two (22) respondents returned surveys equating to an $88 \%$ response rate. The total surveys returned became the sample size for analyzing results. Please see the Appendix A for the survey questionnaire. Survey results referencing the respective questions are analyzed below.

All Survey Responses Analyzed: Calculations derived the standard deviation, mean, median and mode of the responses. Specific question and respondent categorized those response results.

Since the Lickert scale used for this survey was defined by 1 representing least favored (strongly disagree) and 4 most favored (strongly agree), table 1 indicates that the most favored of the survey questions, question 3, received a 3.73 mean. This question dealt with employee satisfaction to their company benefit package. The least favored response had a mean of 1.64. This was question 12, and it asked employee opinion regarding the use of forced ranking to corporate morale.

Proceedings of the 2003 American Society for Engineering Education Annual Conference and Exposition Copyright (C) 2003, American Society for Engineering Education 
The questions that were of greatest importance to this research were questions $8,9,10 \&$ 12. These focused on morale, quality of work life and the use of forced ranking as part of the overall performance appraisal process. All of these questions had a mean ranging from 1.64 to 2.77. This indicates that responses fell between strongly disagree and undecided. The range of standard deviation for these questions was from 0.81 to .96 .

\section{Table 1}

Standard Deviation, Mean, Median and Mode - All Responses

$\begin{array}{rccccccccccccc}\begin{array}{c}\text { Question } \\ \text { Results }\end{array} & \text { Q1 } & \text { Q2 } & \text { Q3 } & \text { Q4 } & \text { Q5 } & \text { Q6 } & \text { Q7 } & \text { Q8 } & \text { Q9 } & \text { Q10 } & \text { Q11 } & \text { Q12 } \\ \text { Total } & 74 & 72 & 82 & 59 & 71 & 45 & 61 & 44 & 61 & 57 & 50 & 36 \\ \text { St Dev } & & & & & & & & & & & & \\ \text { Mean } & 0.79 & 0.88 & 0.55 & 0.84 & 0.92 & 0.84 & 1.02 & 0.93 & 0.81 & 0.96 & 1.03 & 0.90 \\ \text { Median } & 4 & 4.27 & 3.73 & 2.68 & 3.23 & 2.05 & 2.77 & 2.00 & 2.77 & 2.59 & 2.27 & 1.64 \\ \text { Mode } & 4 & 4 & 4 & 3 & 3.5 & 2 & 3 & 2 & 3 & 2 & 2 & 1 \\ & & & & & & 4 & 2 & 2 & 2 & 2 & 2 & 2 & 1\end{array}$

In addition to analyzing the results for individual questions, data was analyzed regarding the overall response by each respondent. These values were then tabulated to obtain a lone voice of employee opinion. Results indicated that collective response produced a mean of 2.70 with a standard deviation of 0.93 (see table 2). In comparing this overall response figure with the individual responses from questions $8,9,10 \& 12$, similar mean and standard deviation values are evident. All values fell within one standard deviation.

Table 2

Standard Deviation, Mean, Median and Mode of Total Response

\begin{tabular}{|c|c|c|c|}
\hline Respondent Results & Total & Avg & St Dev \\
\hline $\begin{array}{l}\text { Mean } \\
\text { Median } \\
\text { Mode }\end{array}$ & $\begin{array}{c}32.36 \\
32 \\
40\end{array}$ & $\begin{array}{l}2.70 \\
2.67 \\
3.33\end{array}$ & $\begin{array}{l}0.93 \\
0.95 \\
0.75\end{array}$ \\
\hline
\end{tabular}

In addition, once data collection was completed, scores from the control $\left(\mu_{1}\right)$ and experimental $\left(\mu_{2}\right)$ groups were compared to determine if there was a statistically significant difference. The control group refers to respondents whose companies employ the performance appraisal process and additionally use forced ranking to identify a bottom tier of "poor performers." The experimental group is defined as those respondents whose companies use only the performance appraisal process. It was hypothesized that the overall mean (that which is the average of all respondents and questions asked) of the control group would score lower than the experimental group. The overall mean for the experimental group is 2.89 while the mean for the control group is 2.36. Although it is evident that the experimental group scored higher than the control group, it must still be proven that the difference in means is statistically significant with regard to question 12, which focused on the topic of forced ranking and its effect to morale in the appraisal process. To determine this, a number of tests were performed which included analysis of each question related to question 12, dealing with the use of forced ranking. 
Additionally, groupings were made of questions 1,2, 3 and 6 due to their focus on employee satisfaction. Also, questions 8, 9, 10 and 12 due to their focus on the issue of morale. These groupings provided more response counts allowing for more of a clear determinant on relationships and significance within the previously mentioned tests. In addition, collapsing of categories aided in the analysis by reducing the categories from four to two, agree and disagree. All tests were performed at an alpha region of 0.05 .

The null hypothesis is $H_{o}: \mu_{1}=\mu_{2}$. The alternate hypothesis is $H_{1}: \mu_{1} \neq \mu_{2}$. The table below states the null hypothesis and alternate hypothesis.

\begin{tabular}{|l|l|}
\hline \multicolumn{2}{|c|}{ Conditions of the Experiment } \\
\hline Hypothesis: & Conditions \\
\hline $\begin{array}{l}\text { Null Hypothesis: Both means of control and } \\
\text { treatment are equal }\end{array}$ & $H_{o}: \mu_{\text {control }}=\mu_{\text {exp erimental }}$ \\
where, $\quad \begin{array}{l}\text { control }=1 \text { and } \\
\text { experimental }=2\end{array}$ \\
$\begin{array}{l}\text { Alternate Hypothesis: Both means of control and } \\
\text { treatment are not equal. }\end{array}$ & $H_{1}: \mu_{\text {control }} \neq \mu_{\text {experimental }}$ \\
& where, $\quad \begin{array}{l}\text { control }=1 \text { and } \\
\text { experimental }=2\end{array}$ \\
\hline
\end{tabular}

Once a null hypothesis and alternate hypothesis are formed, statistical tests can be administered to determine if the null hypothesis or the alternate hypothesis is tenable. The tables and charts include the results of the aforementioned tests. Table below lists the result of the $t-$ test and the chi-square values follow.

It was clear from the analysis of question 12 that chi-square testing would prove ineffective due to the size of the sample. Prior to collapse, chi-square for q.12 had a p-value of 0.161, after collapse 0.531, and with Fishers Exact Test was 0.602.

Chi-Square Tests

\begin{tabular}{|c|c|c|c|c|c|c|}
\hline & & Value & df & $\begin{array}{l}\text { Asymp. Sig. } \\
\text { (2-sided) }\end{array}$ & $\begin{array}{l}\text { Exact Sig. } \\
\text { (2-sided) }\end{array}$ & $\begin{array}{l}\text { Exact Sig. } \\
\text { (1-sided) }\end{array}$ \\
\hline Pearson Chi-Square & & $.393^{b}$ & 1 & .531 & & \\
\hline Continuity Correction & a & .003 & 1 & .958 & & \\
\hline Likelihood Ratio & & .382 & 1 & .537 & & \\
\hline Fisher's Exact Test & & & & & .602 & .465 \\
\hline $\begin{array}{l}\text { Linear-by-Linear } \\
\text { Association }\end{array}$ & & .375 & 1 & .540 & & \\
\hline $\mathrm{N}$ of Valid Cases & & 22 & & & & \\
\hline
\end{tabular}

a. Computed only for a $2 \times 2$ table

b. 2 cells $(50.0 \%)$ have expected count less than 5 . The minimum expected count is 1.45 .

With the questions grouped by satisfaction and morale, one can determine if there is a correlation between respondents' morale and the use of forced ranking.

Proceedings of the 2003 American Society for Engineering Education Annual Conference and Exposition Copyright (C) 2003, American Society for Engineering Education 
Descriptive statistics and histograms for satisfaction and morale scores for each group.

group $=$ experimental

Descriptive Statistics a

\begin{tabular}{|l|r|r|r|r|r|}
\hline & N & \multicolumn{1}{|c|}{ Minimum } & Maximum & \multicolumn{1}{|c|}{ Mean } & Std. Deviation \\
\hline pc satisfaction score & 14 & 9 & 16 & 13.29 & 1.899 \\
pc morale score & 14 & 4 & 10 & 6.71 & 1.978 \\
Valid N (listwise) & 14 & & & & \\
\hline
\end{tabular}

a. group = experimental

$$
\text { group }=\text { control }
$$

Descriptive Statistics ${ }^{a}$

\begin{tabular}{|l|r|r|r|r|r|}
\hline & N & \multicolumn{1}{|c|}{ Minimum } & Maximum & \multicolumn{1}{c|}{ Mean } & Std. Deviation \\
\hline pc satisfaction score & 8 & 9 & 13 & 10.88 & 1.458 \\
pc morale score & 8 & 3 & 10 & 5.38 & 2.200 \\
Valid N (listwise) & 8 & & & & \\
\hline
\end{tabular}

a. group $=$ control
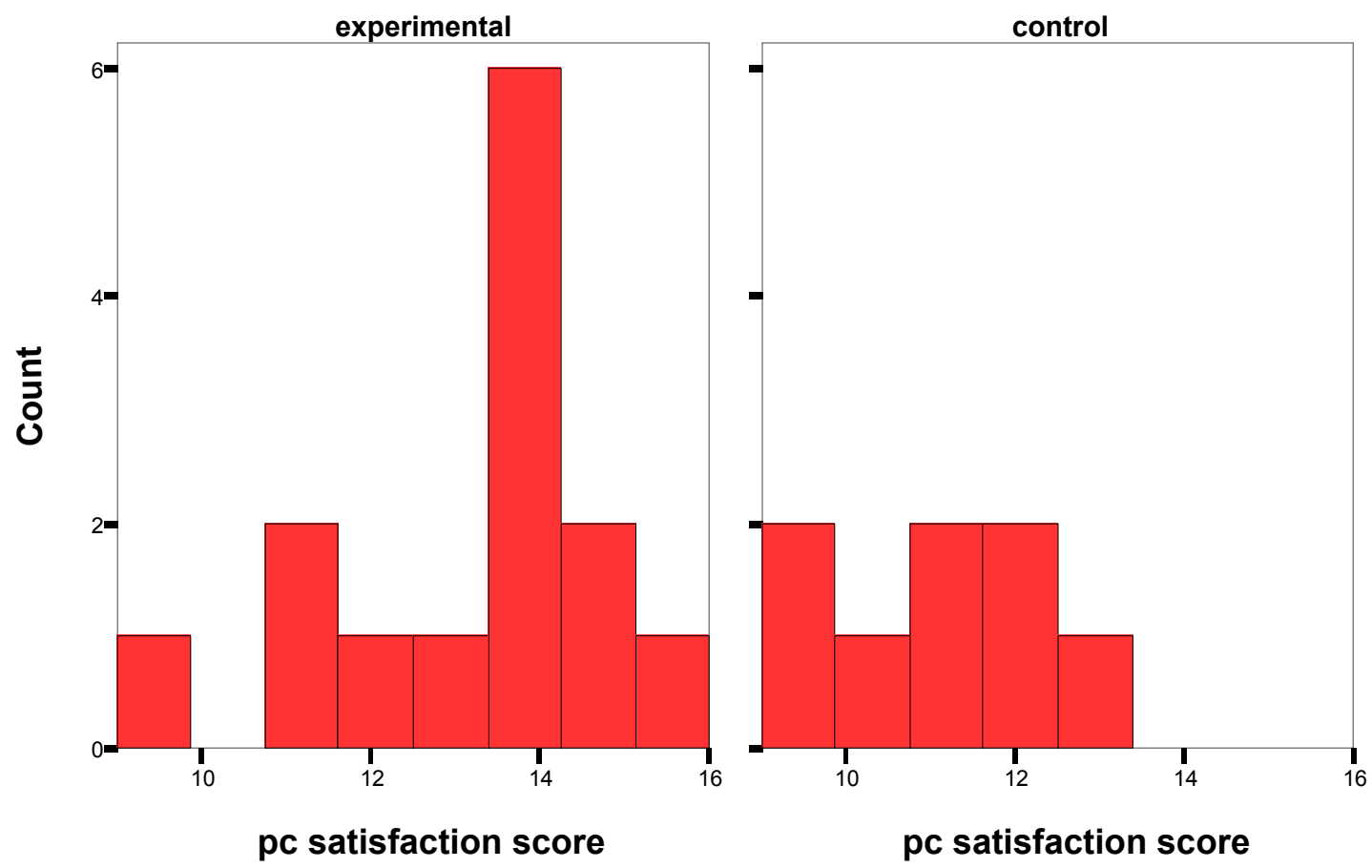

Proceedings of the 2003 American Society for Engineering Education Annual Conference and Exposition Copyright (C) 2003, American Society for Engineering Education 

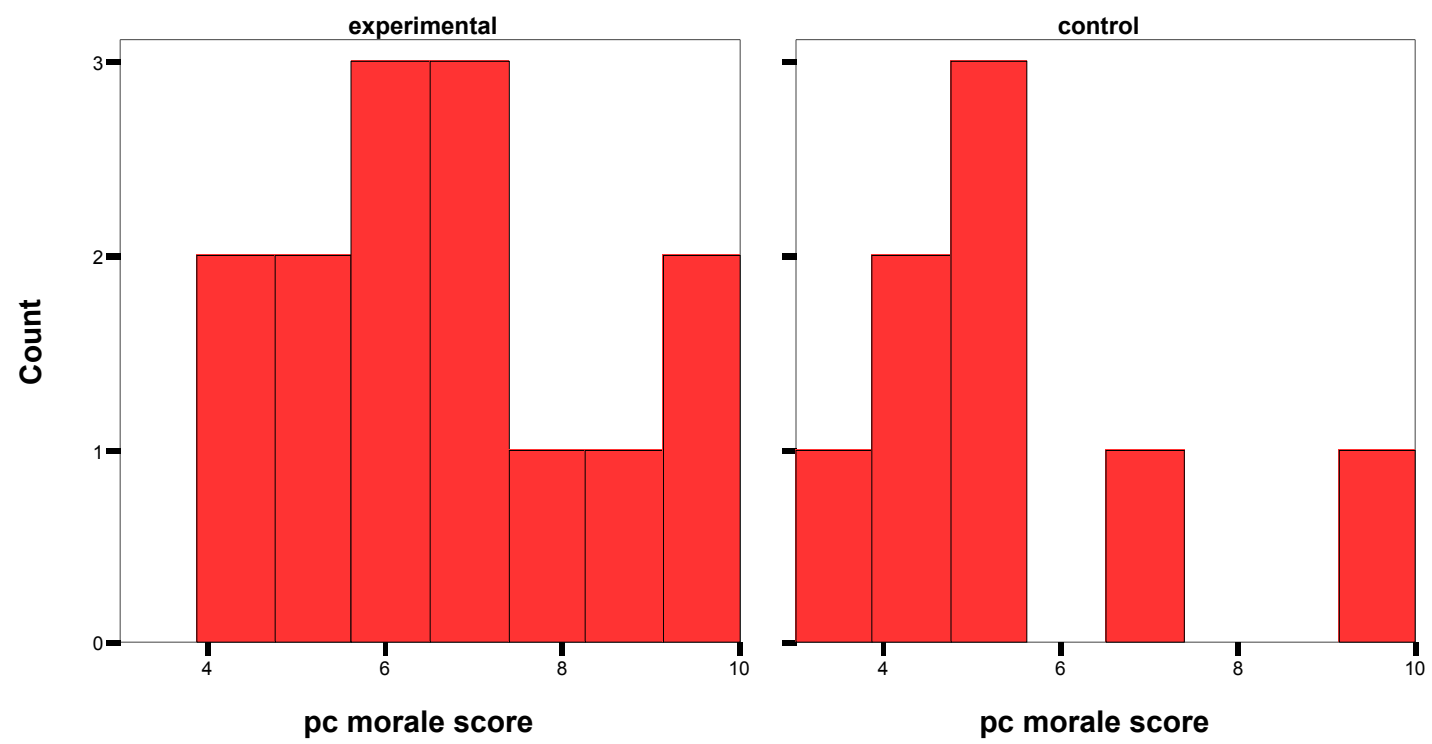

It is evident that the small sample size has a major role in the histogram distortion. One change in response may distort the graphs adversely compelling us to conclude, although mistakenly, that a normal distribution exists.

Finally, the T-Test indicates no statistical significance with regard to morale. The table below defines a T-test of 1.468 and a $p$-value of 0.158 . Yet, a statistical significance exists with regard to the effect of forced ranking on employee satisfaction. T-Test for satisfaction produced a result of 3.096 with a p-value of 0.006 in 20 degrees of freedom.

T-Test

Group Statistics

\begin{tabular}{|ll|r|r|r|r|}
\hline & group & $\mathrm{N}$ & Mean & Std. Deviation & $\begin{array}{c}\text { Std. Error } \\
\text { Mean }\end{array}$ \\
\hline pc satisfaction score & experimental & 14 & 13.29 & 1.899 & .507 \\
& control & 8 & 10.88 & 1.458 & .515 \\
\hline pc morale score & experimental & 14 & 6.71 & 1.978 & .529 \\
& control & 8 & 5.38 & 2.200 & .778 \\
\hline
\end{tabular}

Independent Samples Test

\begin{tabular}{|ll|r|r|r|r|}
\hline \multirow{2}{*}{} & & \multicolumn{3}{|c|}{ t-test for Equality of Means } \\
\cline { 3 - 7 } & & $\mathrm{t}$ & $\mathrm{df}$ & \multicolumn{2}{c|}{$\begin{array}{c}\text { Mean } \\
\text { Difference }\end{array}$} \\
\hline pc satisfaction score & Equal variances assumed & 3.096 & 20 & .006 & 2.41 \\
\hline pc morale score & Equal variances assumed & 1.468 & 20 & .158 & 1.34 \\
\hline
\end{tabular}


Since the p-value of 0.006 is less than 0.05 , the null hypothesis is accepted with a $95 \%$ confidence level, that forced ranking, or the lack of it, affects the level of employee satisfaction. In addition, since the p-value of 0.158 is greater than the alpha region of 0.05 , the null hypothesis is rejected that forced ranking affects employee morale.

\section{CONCLUSIONS}

Although the Wiley survey results [17] indicated a clear evidence that forced ranking affects morale adversely, it failed to conclusively determine that forced ranking has a statistically significant adverse effect on employee compared to just the use of "any other alternative" performance evaluations. The hypothesis statement defined that the survey focus would shed light on these areas. This seemed vital due to the fact that a business would be more inclined to support change when they knew it would eventually affect the organization's overall productivity, profit, efficiency, effectiveness, and finally the morale within the organization.

A number of changes need to occur for future data collection to be more illuminating. First, the survey must incorporate additional questions discussing the role of forced ranking to profit and productivity. Secondly, the questions must be offered a second and third time in a restated format, thus confirming or validating initial respondent response. Finally, increase the sample size to potentially receive a statistically significant difference.

\section{RECOMMENDATIONS}

Based on the findings and lack of statistically significant results, further research and analysis should be performed to determine if there is a need for eliminating forced ranking within performance evaluation process. Those actions may include petitioning the National Labor Relations Board to examine the fair and lawful practice of using forced ranking as a valid employment business tool. Others may include sanctions, by the federal government to businesses under federal contract, to remove the practice of forced ranking or face the penalty of fines and lost business. An action more likely to occur is the development of a more effective performance appraisal tool; an appraisal tool identifying the "poor performer" without using fear tactics, disrupting corporate teamwork, or the personal devastation caused by destroying or irrevocably harming the esteem of the employee.

Finally, the intent of this study has been to show evidence against the use of forced ranking systems by understanding the precept, "Treat people as if they were what they should be, and you help them become what they are capable of becoming." -- Johann Von Goethe 


\section{REFERENCE}

[1] Oberg, W. (2002). Make performance appraisal relevant. [On-line]. Available: Http://www.unep.org/restrict/pas/paspa.htm

[2] Grote, D. (2000, January/February). Performance appraisal re-appraised. Harvard Business Review, 78, p. 21.

[3] Knudson, M.J. (1989). Leadership development for the middle managers of higher education: Harvard's management development program. EDD Dissertation, Harvard University. Ann Arbor: UMI Dissertation Services.

[4] Khan, Hamid (Spring 2002). Dependable correlates of effective professional development of technical personnel, $21^{\text {st }}$ Century Engineer, 2(2).

[5] Abernathy, W.B. (1996). The sin of wages. U.S.: PerfSys Press.

[6] Shellenberger, S. (1992, October 19). Firms often misjudge what employees want. The Wall Street Journal, 227, p. B1. and Shellenberger, S. (2000, January 26). To win the loyalty of your employees, try a softer touch. The Wall Street Journal, 235, p. B1.

[7] Toth, S. (1999, July 19). What workers want from employers. San Diego Business Journal, 20, pp. 15-18.

[8] Longenecker, C. O. \& Fink, L. S. (1999 September/October). Creating effective performance appraisals. Industrial Management, 41, pp. 18-23.

[9] Stone, C. L. (1996, July). Analyzing business performance: counting the 'soft' issues. Leadership \& Organization Development Journal, 17, pp. 21-30.

[10] Glover, R. B. (1996, November). Why are we ignoring performance appraisal research? Parks \& Recreation, 31, pp. 25-26.

[11] Donaldson, S. L., Sussman, S., Dent, C. W. Severson, H. H. \& Stoddard, J. L. (1999, August). Health behavior, quality of work life, and organizational effectiveness in the lumber industry. Health, Education \& Behavior, 26, pp. 579-592.

[12] Briksin, A. (1996, December). Fear and learning in the workplace. The Journal for Quality and Participation, 19, pp.28-34.

[13] Martin, J. (1999, April). Building morale keeps employee spirits high in tough times. H.R. Focus, 76, pp. 9-10.

[14] Zigon, J. (1998). Forced ranking performance appraisal/compensation plan. [On-line]. Available: Http://www.hronline.com/forums/hrnet/9811/msg00183.html

[15] Deets, N. R. \& Tyler, D. T. (1986, April). How Xerox improved its performance appraisals. Personnel Journal, $\underline{65}$, pp. 50-52.

[16] Hitchcock, Darcy. (1996, December). What are people doing around peer review? The Journal for Quality and Participation, 19, pp.52-55.

[17] Wiley, Tim (2002) A study in opposition to the effectiveness of employee performance when using a forced ranking system. Unpublished Thesis, Master of Science in Technology (MST), Northern Kentucky University," Khan, Hamid Thesis Advisor.

Proceedings of the 2003 American Society for Engineering Education Annual Conference and Exposition Copyright (C) 2003, American Society for Engineering Education 
TIM WILEY is a graduate of Northern Kentucky University with a Bachelor of Science degree. His major is Industrial Education with a minor in Construction. He has also completed coursework towards a Master of Science and Technology degree, from the same institution, and will graduate in June 2003. Mr. Wiley is a former trainer, with the 20-20 Group, of sales force automation software and currently Program Development Manager for the Association for Facilities Engineering (http://www.afe.org). In addition, he is a member of the Golden Key National Honor Society and is presently working on a draft of his first book entitled, the Soul of Business. During his undergraduate college career, he was elected to the Scholar, Dean and Honors lists at Northern Kentucky University. His Honors appointment came while working full time with a local utility.

HAMID KHAN is an Associate Professor at Northern Kentucky University. He teaches in the Technology Management track of the Master of Technology Programs. His teaching interests are in Research, Development and Management of Technology. His research interest is in the Management Development of Technical Personnel engaged in Engineering and Engineering Technology. Hamid has a BS in Mechanical Engineering, MS in Industrial Engineering, MBA in Management, and a Doctorate in Education. He has contributed papers to ASEE and Frontiers in Education conferences, and to Journals of Engineering and Engineering Technology. Dr. Khan is a registered Professional Engineer and has offered every year his professional services to TAC of ABET program evaluation for strengthening engineering technology curricula and personnel. 
Appendix A

ET Manager/Employee Opinion Survey

(Directions: mark the appropriate response based on your opinion of the question.)

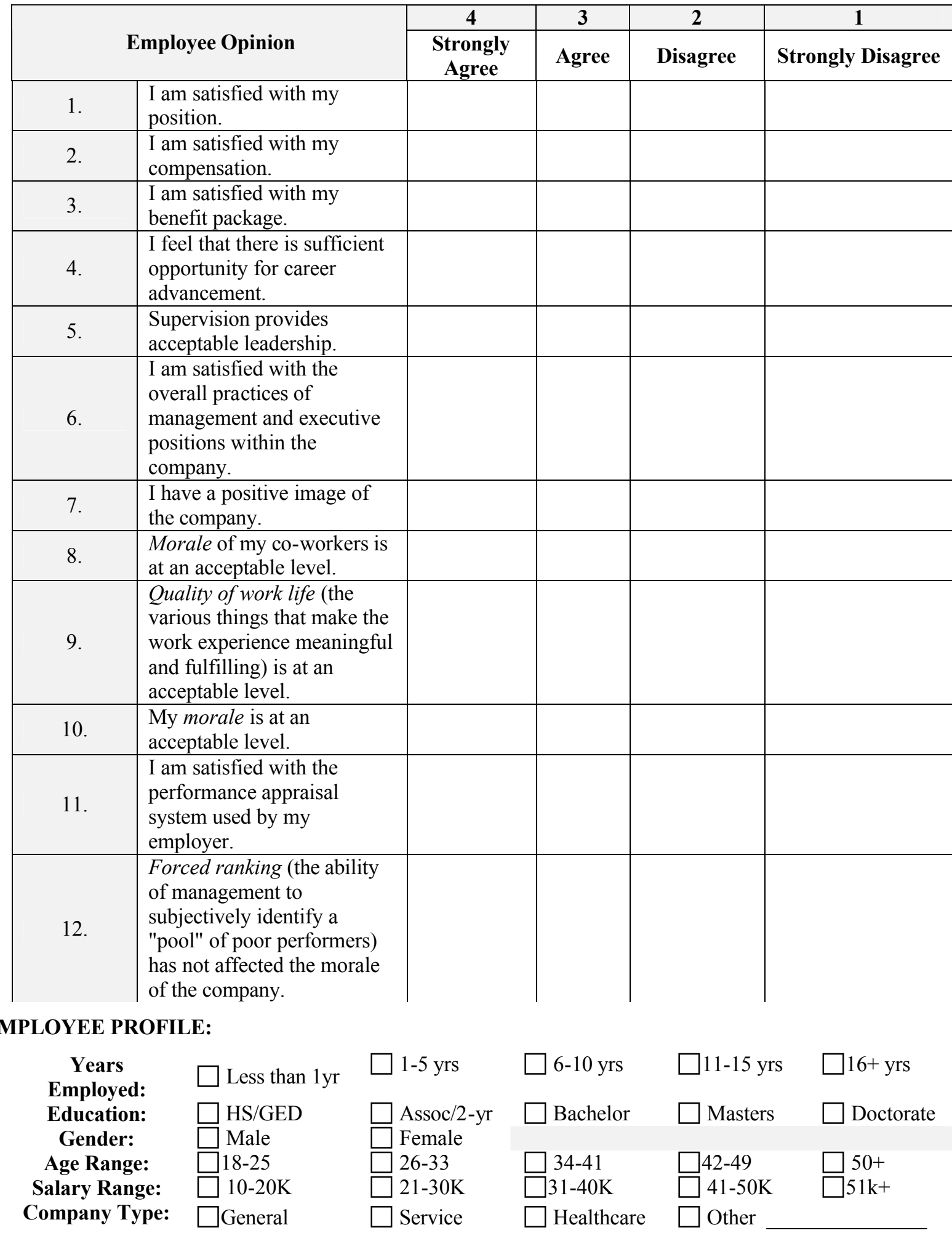

Proceedings of the 2003 American Society for Engineering Education Annual Conference and Exposition Copyright (C) 2003, American Society for Engineering Education 